\title{
ENHANCEMENT OF POWER QUALITY USING FUZZY LOGIC CONTROLLED DSTATCOM
}

\author{
Pandiaraj R, \\ Department of Electrical and Electronics Engineering, \\ St. Peter's Institute of Higher Education and Research, \\ Avadi, Chennai, India \\ pandiaraj.r@gmail.com \\ Dr Rani Hemamalini R, \\ Department of Electronics and Communication Engineering, \\ St. Peter's Institute of Higher Education and Research, \\ Avadi, Chennai, India \\ ranihema69@gmail.com
}

Submitted: Feb, 07, 2020 Revised: Apr, 21, 2020 Accepted: May, 02, 2020

\begin{abstract}
End users of electricity want to receive a quality and reliable electric power without interruption all the time throughout year. Even though, power generation station maintains quality, some natural and man-made sources affect the quality of electric power supply being distributed. Various conventional devices are available to improve electric power quality, but their performance is inadequate. The main aim of the work is to design and simulate a system which provides quality and reliable electric power. The system uses Distribution STATic COMpensator (DSTATCOM) to maintain the power at near sinusoidal voltage and at designed frequency. DSTATCOM is a shunt connected Voltage Source Inverter (VSI) based custom power device, used to mitigate power quality issues. The system also uses the fuzzy logic control algorithm, to control the Pulse Width Modulation (PWM) controllers used in VSI of DSTATCOM.
\end{abstract}

Keywords: Power quality improvement, Enhancement, Mitigation, DSTATCOM, Custom Power Devices, Fuzzy logic VSI.

\section{INTRODUCTION}

Quality electric power means, an electric power at sinusoidal voltage and current, without any distortion and being at its designed level of magnitude and frequency. The quality of electric power generated and transmitted from power generation station is getting affected by various factors like lightning, non-linear loads, poor electrical wiring, grounding, loose connections, adjustable speed drives and power electronic devices etc. For example voltage dip will be faced by a consumer who connected in a line supplying heavy motor load. Voltage dip will occur every time the motor load is turned on. Life support and operation theatre loads in hospitals, food processing plants, semiconductor industries and data processing industries are sensitive loads and requires clean and uninterrupted electricity, since the loss due to power quality issues will be more here. Requirements like these have increased the significance of electric power quality which introduced power electronics based custom power devices (CPDs) [1-4].

Various types of custom power devices are proposed, such as serial, shunt and hybrid devices and are effectively used worldwide. Various types of series and parallel CPDs are analyzed for their performances in mitigating the power quality issues in [5]-[6]. The investigation results show that the voltage and current 
harmonic distortions are considerably reduced by all CPDs, but the parallel CPDs are much superior in performance, particularly in distortion of current harmonics. Additionally, the voltage and current THD index of the overall system can be improved by the parallel CPDs by injecting compensation current to both upstream and downstream loads.

In [7] the performances of CPDs in solving the power quality issues happening in renewable energy sources such as solar and wind energy based distributed generation systems are analyzed. Among the results of various CPDs, the STATCOM provides faster performance. It reduces the system cost due to its small size and it provides both active and reactive power. The author concludes that, the STATCOM as a best choice to mitigate power quality disturbances in renewable energy sources.

DSTATCOM is a Voltage Source Converter (VSC) and is one of the most widely used shunt compensator in transmission and distribution side of flexible AC transmission systems [8]. DSTATCOM provides voltage stabilization, flicker suppression and compensates various power quality disturbances at high speed. It can be used in utility grid, to maintain system stability by injecting or absorbing reactive power from AC line. It can also be used in industries to mitigate the voltage sag/swell and flicker caused by non-linear dynamic loads. Voltage and Current control are the two operating modes of DSTATCOM [8]. In voltage control mode, it adjusts the bus voltage to be sinusoidal without any sag, and in current control mode it adjusts the AC line current to be balanced sinusoids. The components involved in designing the DSTACOM, such as type of switching devices, PWM control algorithms, energy storage devices determines the performance of DSTATCOM.

The output of DSTATCOM can be controlled by controlling the PWM controller. Since the main objective is to respond to the desired state in the quickest possible time, many researchers are working on various control schemes available such as PI, PID and Slide mode control etc [9]. In [10] DSTATCOM is designed using genetic algorithm to control the grid voltage. Results shows that, it regulates the power flow as well as improves the power quality of the grid connected wind energy system. A multiple complex coefficient filter $2^{\text {nd }}$ order generalized integrator based controller is designed in [11] to mitigate the power quality problems of weak grid. About reduction of DC voltage requirement in DSTATCOM connected with photovoltaic cell and line interactive uninterruptible power supply is discussed in [12]. The modeling of photovoltaic fed DSTATCOM for harmonic reduction and voltage regulation is presented in [13].

This paper presents a design of fuzzy logic controller to control the PWM controller. It is used to obtain switching logic for DSTATCOM. The rest of the article is as follows: Section 2 illustrates the methods and materials of the proposed fuzzy logic based DSTATCOM for quality power supply. The performance of this controller is demonstrated in section 3 with linear resistive-inductive loads through simulation results using Power System toolboxes of Simulink / MATLAB and conclusion of the system is given in the last section..

\section{METHODS AND MATERIALS}

The DSTATCOM is a widely used controller in distribution network for system voltage regulation, reduction of harmonics, reduction of transient voltage disturbances and for compensating the loads. It can be constructed using both VSI and Current Source Inverter (CSI). But CSI topology is not used in practice to construct DSATCOM controller, because of higher losses compared to CSI topology. Also the reverse blocking semiconductor switch creates more losses. The 
phase synchronized output voltage of DSTATCOM compensates for inductive and capacitive currents linearly and continuously. By controlling the phase angle difference between the DSTACOM output voltage and line voltage, it is possible for the active and reactive power trade between the power system and the DSTATCOM.

The DSTATCOM is simulated in order to verify functionality and how, it improves the quality of distribution power. The basic block of the DSTATCOM is shown in Figure 1. As shown in Figure, VSC is powered by a DC source and output of VSC is connected to an AC system via a transformer. Here, the DC capacitor is acting as constant DC voltage source. The reactive power to the AC system is compensated by DSATCOM, when the output voltage of DSTATCOM is higher than line voltage and the current goes out of the DSTATCOM. The reactive power is absorbed from the AC system, when the output voltage of DSTATCOM is lower than line voltage and the current is flowing from AC line to the DSTATCOM.

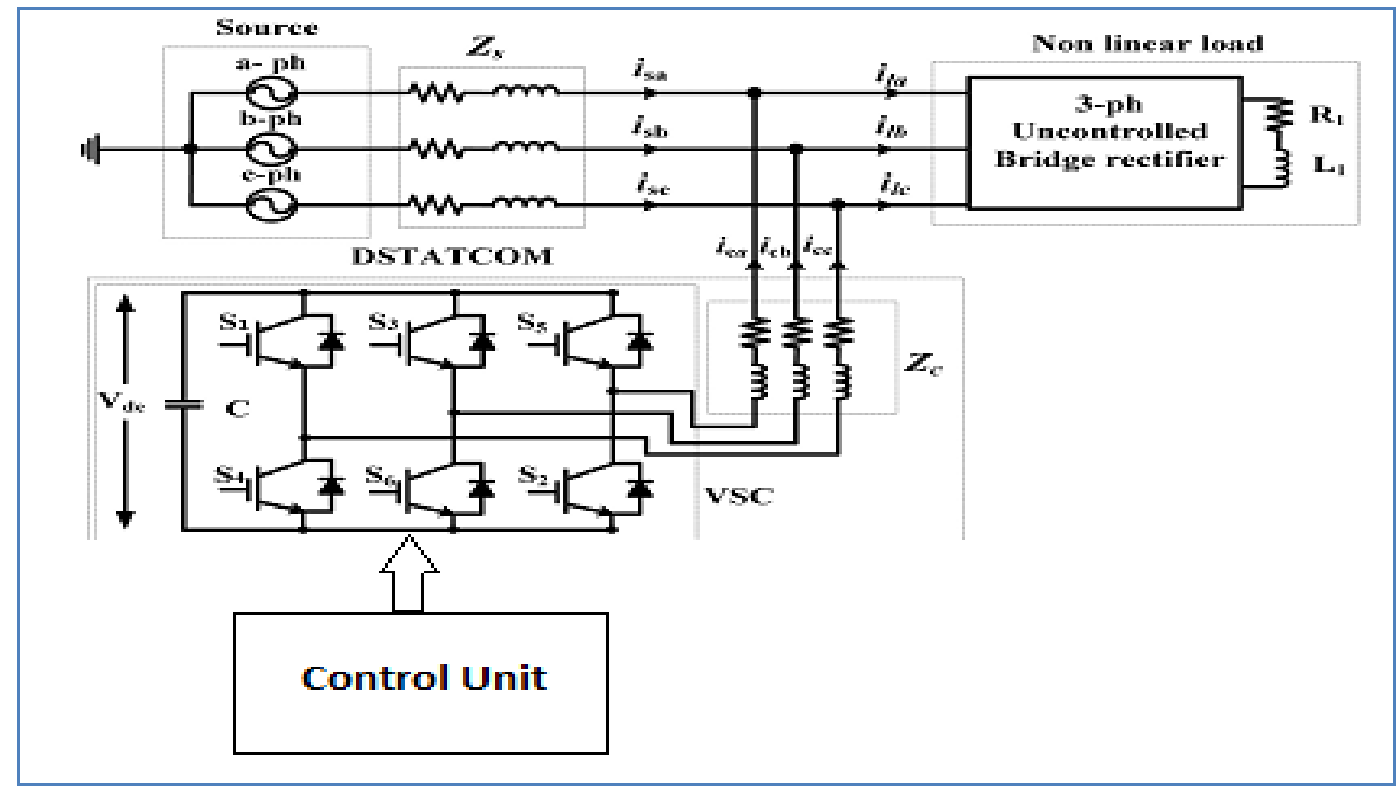

Fig. 1 Block diagram of DSTATCOM

The simulation diagram of DSTATCOM constructed in MATLAB is shown in Figure 2. The DSTACOM subsystem is shown in Figure 3. The DSTATCOM is modeled using a 3 phase AC source, distribution line, MOSFET based 3 phase VSC, a coupling transformer and a high power induction machine load. All these blocks were taken from SimPower toolbox. Fault is injected in the circuit using 3 phase fault block. DSTATCOM is added to line using a breaker. When fault occur the breaker trips and connects the DSTATCOM to AC line to inject compensating voltage. Scope block available in SimPower toolbox is used to plot the voltage and current waveforms coming out of the voltage and current measurement blocks. These voltage and current waveforms are connected to rms block. The rms value of voltage and current waveforms are used to measure the active and reactive power. The DSTACOM can be supplied from the main transmission line through a transformer, an uncontrolled bridge rectifier and a filter to smoothen the DC voltage. All voltage and current waveforms with and without DSTACOM is captured using the Scope block. The faulted and corrected voltage waveforms are obtained from MATLAB simulation. 
Int. J.Adv.Sig.Img.Sci, Vol. 6, No.1, 2020

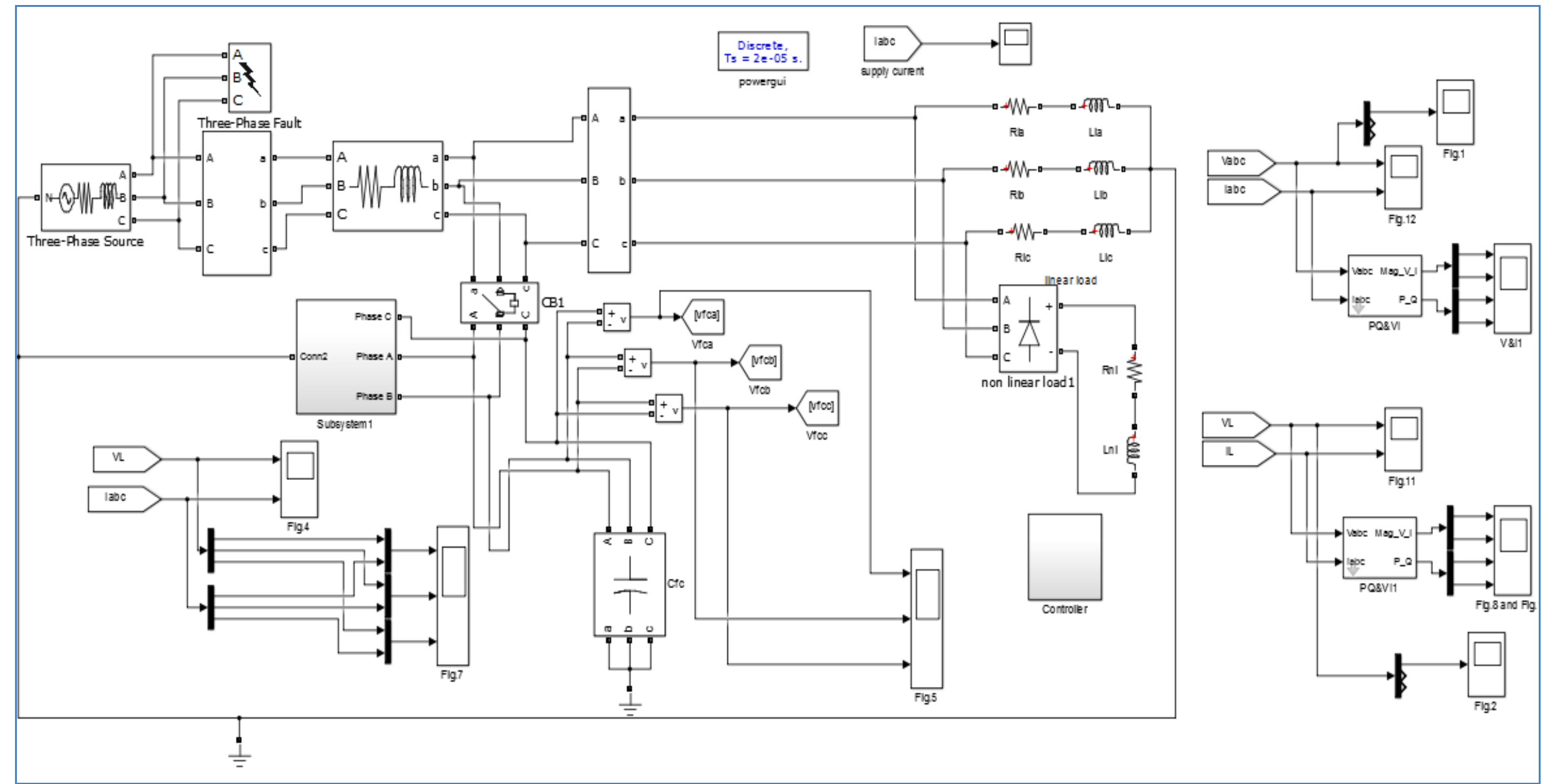

Fig. 2 MATLAB simulation model of DSTATCOM 
Int. J.Adv.Sig.Img.Sci, Vol. 6, No.1, 2020

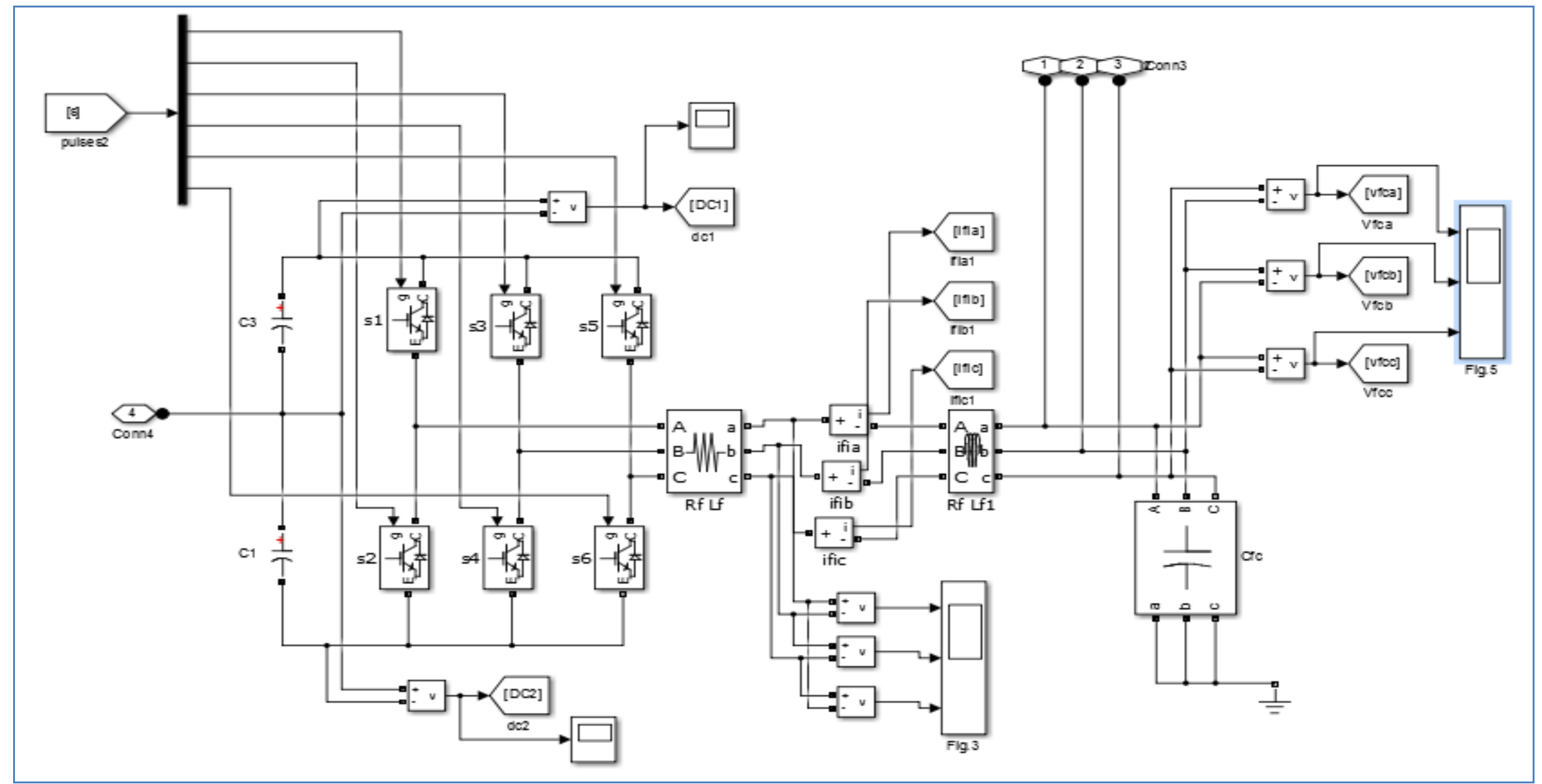

Fig. 3 DSATCOM Subsystem 


\section{RESULTS AND DISCUSSION}

The simulation is done with and without DSTACOM to evaluate the performance of the fuzzy controlled DSTATCOM. The simulation results are taken in both cases and the results are shown.

In case 1 , the simulation is done without the inclusion of DSTATCOM and the waveforms are captured. The total simulation is run for a period of 1.5 second and between $0.5 \mathrm{sec}$ and 1 second the fault is injected. During the injection of fault, there is a sag in supply voltage waveform for the period of 0.5 second to 1 second. The affected voltage waveform due to the injection of fault is shown in Figure 4. In case 2 the DSTACOM block is added to the power system during the injection of fault. It compensated the voltage sag caused by the three phase fault block. The corrected voltage waveform due to voltage injected by DSTATCOM is shown in Figure 5.

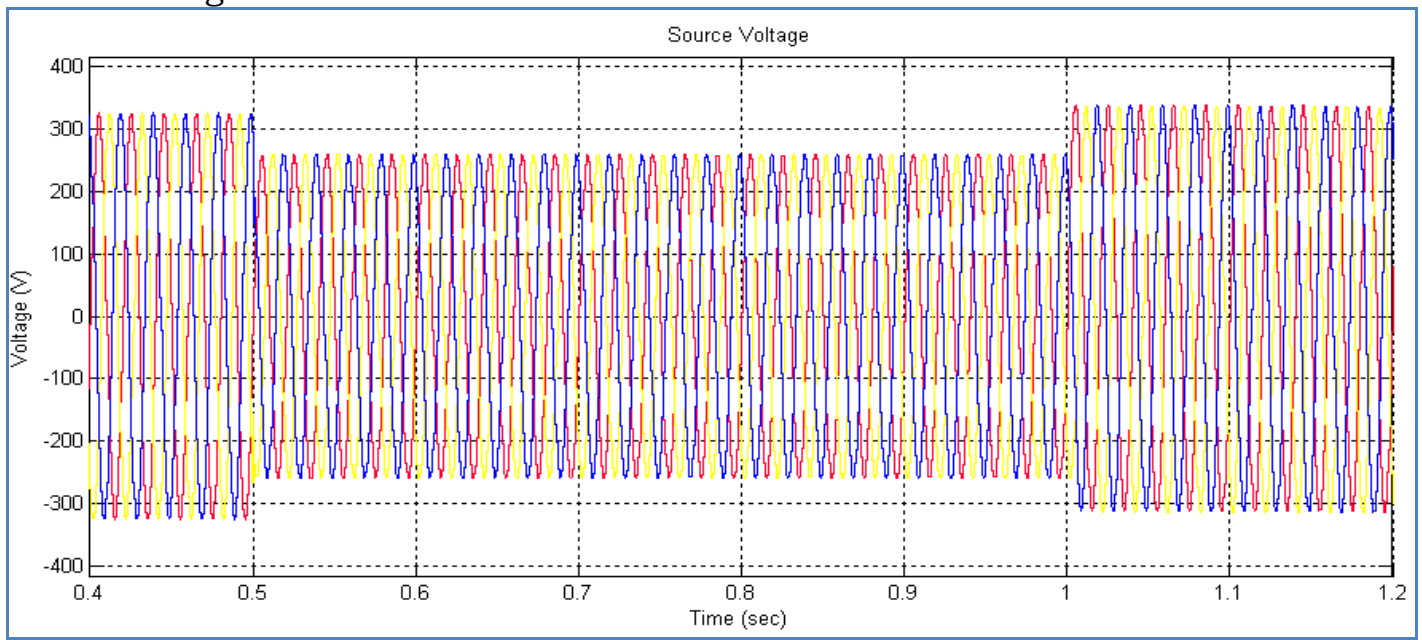

Fig. 4 Supply voltage during fault injection

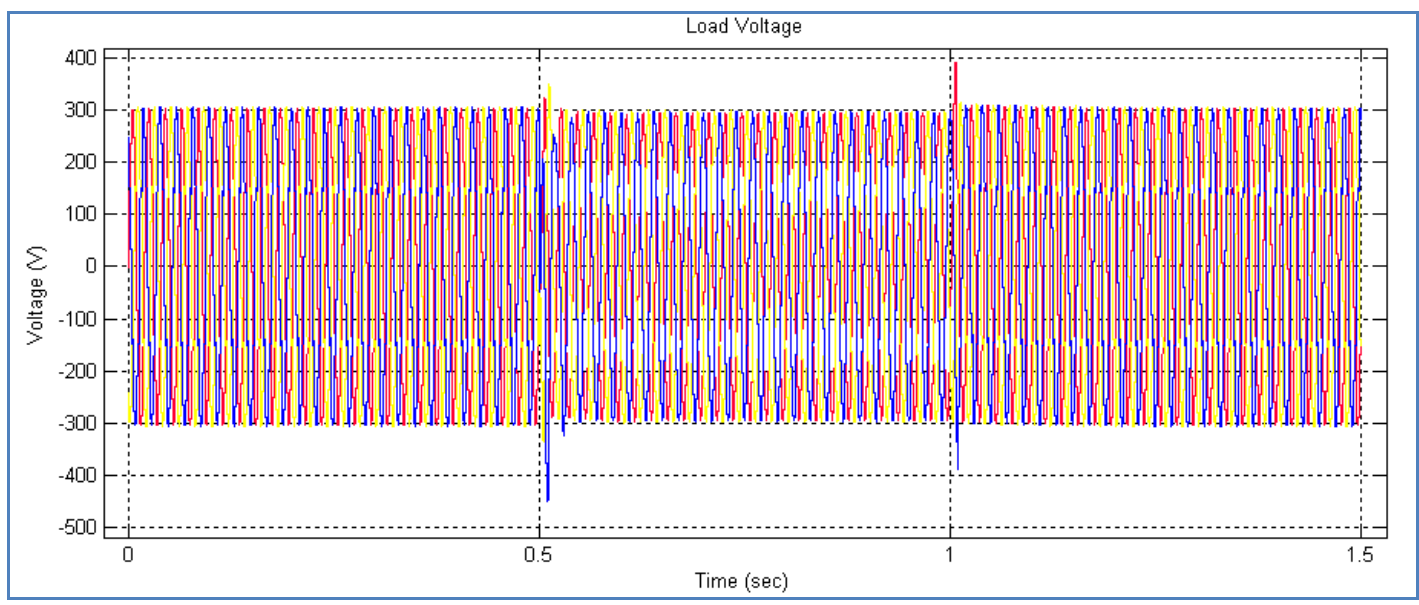

Fig. 5 Voltage across load after compensation 
It is observed from Figure 5 that, the addition of DSTATCOM to the AC line, corrected the voltage sag problem immediately after its addition. Since the DSTACOM is designed using MOSFET switching device based VSI, the whole circuit is included for Fast Fourier Transform (FFT) analysis to calculate the Total Harmonic Distortion (THD). The Powergui FFT analysis tool available in MATLAB is used for this analysis. The result of FFT analysis is shown in Figure 6. From the analysis the THD for load voltage is obtained and it is $4.24 \%$.

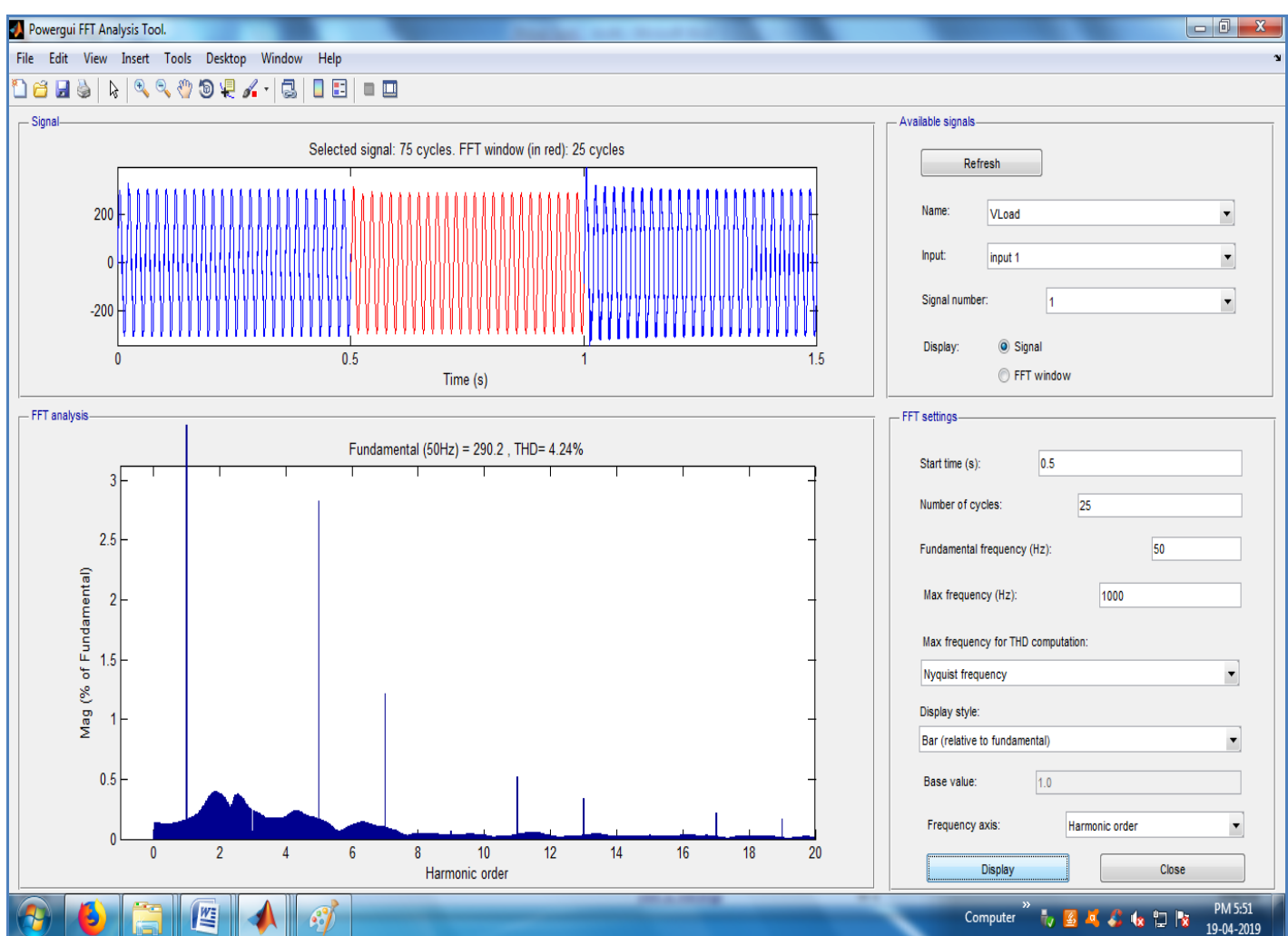

Fig. 6 FFT analysis for THD

\section{CONCLUSION}

Power compensating device using DSTATCOM with fuzzy logic is modeled and simulated using MATLAB/Simulink software. The DSTATCOM is a solid-state device employing power electronic switches to achieve flexible reactive power injection at the load end of a transmission system. The system uses MOSFET based 6-pulse inverter configuration in 3 phase VSC. By increasing the output voltage of DSTATCOM, reactive power is generated and supplied to the AC system. By controlling the firing angle of MOSFETs the magnitude of the DSTATCOM terminal voltage is controlled. DSTATCOM model tested on MATLAB/Simulink is shown that it can mitigate the voltage sag at very fast. It may further reduce the sensitive loads from trips due to voltage sag. 


\section{REFERENCES}

[1]. A. Ghosh \& G. Ledwich, "Power Quality Enhancement using Custom Power Devices", Springer science \& business media, 2002.

[2]. $\quad$ C. Sankaran, "Power Quality", 2002, CRC Press, Boca Raton.

[3]. J. Arrillaga, N.R. Watson \& S. Chen, "Power System Quality Assessment", 2000, Wiley, New York.

[4]. R.C. Dugan \& M.F. Granaghan, "Electrical Power Systems Quality", McGraw-Hill, 2004.

[5]. M. Farhoodnea, A. Mohamed \& H. Shareef, "A comparative study on the performance of custom power devices for power quality improvement", IEEE Conference In Innovative Smart Grid Technologies-Asia, 2014, pp. 153-157.

[6]. M.A.A. Yahiya, \& M.A.R. Uzair, "Performance analysis of DVR, DSTATCOM and UPQC for improving the power quality with various control strategies", IEEE Biennial International Conference in Power and Energy Systems: Towards Sustainable Energy, 2016, pp. 1-4.

[7]. E. Hossain, M.R. Tür, S. Padmanaban, S. Ay \& I. Khan, "Analysis and Mitigation of Power Quality Issues in Distributed Generation Systems Using Custom Power Devices", IEEE Access, Vol. 6, 2018, pp. 1681616833.

[8]. M.B. Latran, A. Teke \& Y. Yoldaş, "Mitigation of power quality problems using distribution static synchronous compensator: a comprehensive review", IET power electronics, Vol. 8, No. 7, 2015, pp. 1312-1328.

[9]. B. Singh, A. Adya, A.P. Mittal \& J.R.P. Gupta, "Modeling, design and analysis of different controllers for DSTATCOM", In Joint International Conference on Power System Technology and IEEE Power India Conference, 2008, pp. 1-8.

[10]. H.F. Mohamed, N.H. Saad \& K.A.A.S. Eldin, "Moderation of Voltage Sag and Swell in Grid Connected Wind Energy Based PMSG by DSTATCOM", Twentieth International Middle East Power Systems Conference, 2018, pp. 433-439.

[11]. P. Chittora, A. Singh \& M. Singh, "Simple and efficient control of DSTATCOM in three-phase four-wire polluted grid system using MCCFSOGI based controller", IET Generation, Transmission \& Distribution, Vol. 12, No. 5, 2017, pp. 1213-1222.

[12]. G. Satpathy \& D. De, "DC Voltage Reduction in PV connected LV DSTATCOM with In-Phase Series Voltage Injection and Improved Transformer Ratings", IEEE $4^{\text {th }}$ Southern Power Electronics Conference, 2018, pp. 1-8.

[13]. P.K. Ray, S. Mishra, G.H. Beng \& S.K. Kollimalla, "Improvement of power quality using an average model of a new hybrid PV-DSTATCOM", IEEE International Conference on Industrial Technology, 2017, pp. 440-445. 